A EMERGÊNCIA DA TEORIA SOCIOLÓGICA Sociológica que eles construíram, de modo que dezesseis capítulos conformam a obra. No último capítulo, o leitor encontrará pistas analíticas que o ajudarão a perceber a influência dos autores clássicos nas teorizações da Jesus Izquierdo*

Lançado no final do ano de 2016, o livro A Emergência da Teoria Sociológica (Turner, 2016) poderia ser recepcionado como um genuíno handbook. É um manual que condensa, de forma refinada, o mais significativo do pensamento social que permitiu, durante os anos de 1830 a 1930, construir uma nova ciência: a Sociologia. Assinam como autores do livro Jonathan H. Turner, Leonard Beegley e Charles H. Power. Os três usufruem de amplo reconhecimento acadêmico em virtude de suas publicações teóricas, com tradução para diversos idiomas.

O livro traz a lume conceitos e proposições metodológicas de autores considerados clássicos da Sociologia, como é o caso de Karl Marx, Max Weber e Emile Durkheim. Resgata as ideias de Augusto Comte e Herbert Spencer, pensadores brilhantes que, em contextos diferentes, influenciaram a formação do pensamento sociocientífico do século XIX. São também apresentadas as contribuições teóricas de Georg Simmel e Georg Herber Mead, cujas ideias foram fundamentais no processo de construção da Sociologia contemporânea que, mais do que as análises estruturais, tomou por escopo o estudo da ação social pelo viés do agente. A cada um desses autores são dedicados dois capítulos: um relativo aos dados biográficos e outro voltado para a Teoria Sociologia contemporânea. Por oportuno, destaquem-se as remissões bibliográficas postas pelos autores no conjunto da obra. Além de serem ilustrativas, as remissões são de grande valia para quem busca fortalecer um conhecimento especializado em um determinado tema sociológico.

À Sociologia pode ser aplicado o postulado epistemológico que define a ciência como uma prática gnosiológica de caráter cumulativo e progressivo. Segundo Comte, a Sociologia é uma ciência que tem por finalidade estudar sistematicamente o universo social. Estando a vida coletiva em um processo permanente de mudança e transformação, desde sua origem, a Sociologia tem se caraterizado como uma ciência destinada a viver um processo de permanente reinvenção conceitual e metodológica. Essa demanda é descrita no primeiro capítulo do livro.

Os autores começam a obra descrevendo o processo através do qual foram construídos métodos de observação da vida social e conceitos que pudessem indicar, com precisão, as propriedades dos fenômenos sociais e suas interconexões causais, a fim de explicar as mudanças que chegaram com a modernidade. Hobbes, Montesquieu, Rousseau, Adam Smith, entre outros filósofos dos séculos XVII e XVIII, pioneiros no estudo da sociedade e sentindo os efeitos da modernidade, formularam as seguintes questões: por que a modernidade emergiu? Como se explica o declínio do feudalismo e a instauração dos modos de organização social capitalista? A resposta a essas questões permitiria compreender por que o mundo moderno emergiu e forneceria elementos para perceber como ele opera. De sua vez, Darwin, Tocqueville, Saint-Simon e outros pensadores sociais do século XIX, mais do que descrever, assumiram como desafio explicar os processos 
de mudança ocorridos em seu tempo. O desejo de explicar esses processos os levou a realizar análises sistemáticas de fenômenos concretos, a estabelecer conexões causais entre esses fenômenos e a elaborar conceitos abstratos e gerais ou, em outras palavras, a construir teorias.

De forma sistemática, no livro são apresentadas diversas teorias. A expressão "Teoria Sociológica” nos remete, por vezes, a uma esfera de caráter filosófico, a uma dimensão onde pairam ideias tingidas de matizes metafísicos que, em princípio, parecem dizer muito pouco sobre o mundo real. No entanto, na redação do livro, os autores zelaram para que os conceitos teóricos se mantivessem atrelados à realidade que possibilitou sua construção. Tal demanda é própria da modernidade. Para os autores, Francis Bacon (1561-1626) deve ser lembrado como o primeiro pensador que plasmou por escrito as diretrizes que definiram o novo modo de estudo no mundo moderno. Segundo ele, é preciso desconfiar de qualquer observação da realidade. É preciso que, antes de legitimar os conceitos formulados, eles sejam confrontados com os fatos observados. A sistematização de dados empíricos e sua posterior expressão em conceitos abstratos possibilitaram extraordinários desdobramentos do conhecimento humano. Da formulação da lei da gravidade, $\infty$ feita por Isaac Newton, aos estudos contempoخे râneos das micropartículas, o princípio axial da prática científica continua sendo o mesmo: a articulação de dados empíricos com conceitos teóricos.

Nos diversos capítulos da obra, os autores mostram que as teorias resultam de abs$\dot{i}$ trações feitas a partir de dados particulares, $\stackrel{\infty}{\infty}$ coletados e analisados por pessoas concretas i em contextos históricos específicos. Essa historicidade demanda que a compreensão de uma teoria seja feita a partir das nuanças que permitiram sua emergência. Noutras palavras, o estudo de uma determinada teoria pressupõe mergulhar no microcosmo social dos autores que a produziram, assim como indagar as condições de vida desses autores, o sistema de pensamento que os influenciou, seus anseios individuais e a forma como orientaram seu modo de pensamento.

Tanto o é que o título dos capítulos que antecedem a apresentação teórica de cada pensador começa assim: "A origem e o contexto do pensamento de [...]”. Tais capítulos poderiam ser catalogados como biografias intelectuais. Com efeito, de forma cronologicamente ordenada, são descritos eventos relevantes da vida do pensador que se pretende apresentar. Além das influências intelectuais dos pensadores, os autores do livro descrevem, com uma narrativa envolvente, diversos episódios que, em certa medida, também pautaram os modos de pensamento e os temas tratados pelos fundadores da Sociologia. Tal como ocorre com a trajetória de cada indivíduo, a obra revela que a vida dos autores clássicos também foi pontuada por episódios dramáticos, outros cômicos, e outros que denotam que de eventos inesperados podem resultar fenômenos extraordinários.

A leitura dessas biografias intelectuais induz a pensar a Sociologia numa perspectiva teleológica, como uma ciência necessária, cuja finalidade é permitir que o homem alcance seu pleno desenvolvimento. Nesse sentido é pertinente lembrar Max Weber, que discorreu sobre a relação estreita existente entre os valores do cientista e sua prática científica. Segundo ele, o interesse por um determinado objeto de estudo surge da relação direta entre uma situação vivida, as questões que ela levanta e seu tratamento científico. Em outras palavras, o desempenho de um cientista está relacionado com sua biografia.

Com efeito, a leitura desses capítulos nos permite conhecer vários exemplos que ilustram essa conclusão. As obras de Marx e Engels não poderiam ter sido concebidas sem o engajamento de ambos nos movimentos operários. Quando Max Weber adoeceu, foi no estudo da ética puritana que encontrou alento para superar o quadro patológico da doença mental de que padecia. Quando enfrentou conflitos afetivos que abalaram seu matrimonio, Weber se interessou 
em estudar temas relativos às tensões que emergem das relações paradoxais entre amor e ascetismo, erotismo e religião. Também é possível pensar que a escolha do suicídio como tema de estudo sociológico tenha resultado mais da inquietação de Durkheim por entender seu ímpeto neurótico do que pela relevância de tal prática como fato social. A rejeição experimentada por George Simmel pelas elites intelectuais alemãs fez com que ele abordasse diversos temas e se expressasse por meio de uma escrita criativa, livre dos limites ditados pelos padrões acadêmicos.

O leitor poderá constatar que, antes dos clássicos da Sociologia, diversos filósofos se perguntaram: Qual é a origem da sociedade? A resposta dada era de ordem filosófica ou, nas palavras de Comte, formulada a partir de categorias metafísicas. Na leitura do livro, tem-se acesso às ideias de filósofos que, entre os séculos XVII e XVIII, com os traços de sua pena, desenharam com maestria a moldura do pensamento ocidental moderno. São referenciadas obras de Tomas Hobbes, John Locke, Adam Smith, Darwin, Newton, Rousseau, Alexis de Tocqueville, Hegel, Kant, Montesquieu, entre outros. As ideias desses pensadores se contradizem, se completam, conflitam entre si e, na tensão dessas oposições, formam escolas ou tradições de pensamento.

Os capítulos dedicados a apresentar a teoria dos fundadores da Sociologia sistematizam e dão coerência aos dados revelados nos capítulos que tratam das biografias intelectuais. No conjunto da obra, os autores revelam que existiu, no começo da teorização sociológica, um elemento apriorístico que permitiu ao homem compreender um fenômeno sem que tal compreensão obedeça, necessariamente, aos cânones científico-racionais. Como fica claro na obra, a teoria, em um primeiro momento, depende mais de tradições de pensamento do que de processos heurísticos realizados por um determinado cientista.

A observação do processo de construção dessas tradições de pensamento pode ser con- siderada como um exercício da Sociologia do Conhecimento. Conceitos e métodos de observação construídos pelos fundadores da Sociologia constituem o resultado de um trabalho analítico realizado em um momento pontual, numa etapa do percurso das ideias e observações da realidade. Articuladas por sua lógica interna e por sua coerência com a realidade fática, essas ideias e observações tecem a história da Sociologia como ciência.

Entre as páginas 447 e 478, o leitor encontrará um "Índice Analítico", uma extensa listagem de conceitos que evidenciam o esforço dos autores por sistematizar a emergência da Teoria Sociológica. Mais de cem conceitos são amplamente discutidos e coerentemente apresentados. É descrito o processo de construção e de utilização de um determinado conceito. Como exemplo da forma como os conceitos são trabalhados na obra, discorreremos sobre o conceito de anomia.

Para os autores, um dos desafios de Durkheim foi o de compreender como se dão as mudanças sociais na modernidade, a exemplo da passagem de uma sociedade tradicional a uma sociedade capitalista. Para o pensador francês, como resultado da divisão do trabalho, a sociedade capitalista foi constituída por um grande número de unidades diferenciadas. Ao descrever esse processo de diferenciação social, ele se pergunta: como é possível preservar os elos de coesão social? A resposta para tal questionamento está na compreensão da função social da divisão do trabalho, a qual diz respeito à promoção da solidariedade ou à integração societal. Nesse contexto, o conceito de anomia descreve um estado de regulação insuficiente das atividades dos indivíduos, de modo que eles se mantêm em uma situação periférica por não se sentirem atraídos ou incluídos pela coletividade. Em outras palavras, o estado de anomia é correlato ao tema da integração social, que havia sido amplamente discutido por Rousseau, Tocqueville e Comte. Esses filósofos construíram uma tradição de pensamento sobre a qual Durkheim formulou 
o conceito de anomia, o qual, como é descrito no capítulo 16, é utilizado na Sociologia Contemporânea através da teorização do conflito.

\section{A Emergência da Teoria Sociológica é} um compêndio de vertentes teóricas concebidas décadas atrás e que continuam fornecendo pistas analíticas à prática sociológica. A leitura do livro é pertinente para cientistas sociais e para pessoas intelectualmente inquietas, para estudiosos que buscam compreender a mecânica da vida social ou ter acesso à história das ideias que alicerçaram a cultura moderna ocidental.

Recebido para publicação em 05 de outubro de 2017 Aceito em 20 de janeiro de 2018

\section{REFERÊNCIAS}

TURNER, Jonathan et al. A Emergência da Teoria Sociológica, 486 p. Petrópolis: Vozes, 2016.

*Jesus Izquierdo - Pós-Doutor em Sociologia pela Universidade Nova de Lisboa. Professor da Unidade Acadêmica de Ciências Sociais da Universidade Federal de Campina Grande. Professor do Programa de Pós-Graduação em Ciências Sociais da UFCG. Coordenador do Grupo Hexis, desenvolvendo pesquisas na área de Cultura e Identidade. Pesquisa temas relacionados com as categorias Gênero, Juventude, Violência e Conflitos Sociais. Entre suas publicações se destaca o livro Meninos Não Choram - a formação do habitus guerreiro nas FARC-EP. Fortaleza: Edições UFC, 2008. Universidade Federal de Campina Grande. Rua Aprígio Veloso, 882 - Universitário, CEP 58429-900, Campina Grande - PB, Brasil. jizvil@yahoo.com.br 